\title{
CHARACTERIZATION OF COATED PRINTS WITH FRAGRANCED MICROCAPSULES
}

\author{
Rastko Milošević ${ }^{1}$ (D), Nemanja Kašiković ${ }^{1}$ (D), Živko Pavlović ${ }^{1}$ (D), \\ Mladen Stančić ${ }^{2}$ (D), Raša Urbas ${ }^{3}$ \\ ${ }^{1}$ University of Novi Sad, Faculty of Technical Sciences, \\ Department of Graphic Engineering and Design, Novi Sad, Serbia \\ ${ }^{2}$ University of Banja Luka, Faculty of Technology, \\ Graphic Engineering Department, Banja Luka, Bosnia and Herzegovina \\ ${ }^{3}$ University of Ljubljana, Faculty of Natural Sciences and Engineering, \\ Department of Textiles, Graphic Arts and Design, Ljubljana, Slovenia
}

\begin{abstract}
Microcapsules are used in various fields of application, such as in pharmacy, medicine, agriculture, chemical industry, construction industry, food industry, biotechnology, electronics. Fragranced and PCM (phase change materials) microcapsules also found their use in the printing and the textile industries, where they are applied in the combination with the appropriate ink or varnish on the desired substrate material. Microcapsules are applied either by coating or by different printing techniques, which main advantage is the ability to transfer the microcapsules onto desired areas of the substrate material without or with as little damage as possible, thus allowing the deposited microcapsules to fulfil their basic functionality. The aim of this research was to investigate the morphologic characteristics of the fragranced microcapsules and the coated prints using selected varnish and different fragranced microcapsules concentrations, as well as to determine how variable concentrations of the applied microcapsules in the varnish affect the optical characteristics of the coated prints. Performed SEM (scanning electron microscopy) and spectrodensitometric analyses of the coated prints revealed that both the coating process without microcapsules, as well as the different fragranced microcapsules' concentration in the coated water-based varnish, significantly affected both the morphologic and the optical characteristics of the coated prints.
\end{abstract}

Key words: fragranced microcapsules, coating, offset printing, morphology, optical characteristics

\section{INTRODUCTION}

Different coatings are used today in the printing industry in order to add a new value to the printed products or to enrich them by enhancing their visual, protective or functional properties (application of different microcapsules' types) (Kipphan, 2001; Gosh, 2006). Microcapsules are used in different fields of application, such as in medicine, pharmacy, agriculture, biotechnology, electronics, chemistry, construction, food, printing and textile industry. They can be applied on various substrates, using numerous transfer techniques (coating or different printing techniques: screen and flexo printing, sheetfed and web offset printing, gravure, pad printing, inkjet and xerography), which enable precise microcapsules' deposition on the specific areas of the printing substrate, though before application they need to be pre-mixed with the printing ink or the printing varnish (Gosh, 2006; Urbas et al, 2017; Starešinič et al, 2011; Rodrigues et al, 2009; Goetzendorf-Grabowska et al, 2004; Goetzendorf-Grabowska et al, 2008; Chovancova et al, 2008; Milošević et al, 2016). In addition to the visual and the tactile aspects of the printed matter, the progress of the printing technology also enabled the integration of scents, by applying microcapsules containing fragrances (Rose, 2007).

Microcapsules are tiny spheres, usually consisting of two parts (core and shell), which enables the encapsulated active agent (core material) to reach the "target" areas without being affected by the environment through which it passes, while its microscopic size allows the consumption of very small active agent quantity (Gosh, 2006; McShane et al, 2009; Dubey et al, 2009; Microtek Laboratories). Microcapsules used in printing applications can be activated by using different activation mechanisms, such as by external pressure, abrasion and heat or light application (Gosh, 2006; Boh et al, 2008; Nelson, 2001; Sensor Products).

Applied microcapsules enable different functionalities to the final, printed product, but they will to a certain extent change basic features of the prints such as physical (thickness, grammage, surface roughness), mechanical and optical characteristics (colour, opacity and print gloss) (Blanco-Pascual, 2014; 
Pavić, 2015; Tarnopol, 2009; Urbas et al, 2015; Manojlović, 2013). A surface characteristic of the printed surface has a huge impact on the type and the amount of the reflected light from the printed surface, which affects the print quality and the overall appearance of the prints. Morphologic characteristics of the prints are dependent on the printing substrate properties, its surface structure (smoothness, roughness), texture, degree of transparency, type of the coating and complex rheological and surface tension properties of the coatings used (Karlović, 2010; Karlović et al, 2011; Satas et al, 2000). Basic properties of the microcapsules, such as morphology, microcapsule formation, size and volume distributions, can be determined using optical, scanning electron microscopy (SEM) or transmission electron microscopy (TEM) in combination with the appropriate image analysis software (Rodrigues et al, 2009; Urbas et al, 2015; Peña et al, 2009).

The aim of this research is to determine basic morphologic and optical characteristics of the functional coatings with scents, produced by an automatic coating technique using water-based varnish in which fragranced microcapsules in water suspension were added, as well as to investigate how different concentrations of the microcapsules in the coating layers affect morphologic and optical characteristics of the coated prints. Conducted SEM and optical characteristics analysis of the produced functional coatings revealed that the application of the microcapsules, in the varnish, significantly affected morphologic and optical characteristics of the coatings.

\section{METHODS}

In this research, for the coating process were used fragranced mono-core microcapsules in water suspension, which were made by modified in situ polymerization method (Šumiga, 2013). The microcapsule core material was made of different essential oils combination, with the fragrances of sage, rosemary and lavender, while the microcapsule shell was made of partially methylated trimethylol melamine (Melamin, Slovenia). As a printing substrate was used a commercially available matte coated paper (GardaMatt Art, Lecta, Spain) which basic characteristics provided by the producer (thickness, basis weight, specific volume and CIE whiteness) were presented in Table 1.

Table 1: Basic characteristics of used paper

\begin{tabular}{|c|c|c|c|c|c|}
\hline Paper & Surface finish & $\begin{array}{c}\text { Basis weight } \\
\text { (ISO 536) }\end{array}$ & $\begin{array}{c}\text { Specific } \\
\text { volume }\end{array}$ & $\begin{array}{c}\text { Thickness } \\
\text { (ISO 534) }\end{array}$ & $\begin{array}{c}\text { CIE-whiteness } \\
\text { (ISO 11475) }\end{array}$ \\
\hline GardaMatt Art & matte coated & $130 \mathrm{~g} / \mathrm{m}^{2}$ & $0.85 \mathrm{~cm}^{3} / \mathrm{g}$ & $111 \mu \mathrm{m}$ & $121.3 \mathrm{CIE}$ \\
\hline
\end{tabular}

The C-375 water-based printing varnish was based on the stabilised water dispersion of acrylic resins (styrene acrylic emulsion), with the addition of the polyethylene wax. Selected varnish is suitable for the protection of the printed packaging in the food industry (without direct contact with the food) and is characterised by its high gloss and abrasion resistance (Cinkarna Celje, Slovenija).

Chosen substrate material was firstly printed using a four-color sheet-fed offset printing machine (KBA Performa 74, Koenig \& Bauer, Germany) using only cyan ink (Diatone ${ }^{\circledR}$ PREMIUM+, Sakata inx, Japan). Printing was done according to standard printing production conditions, using Libra VP digital printing plate (Kodak, USA). Before coating process, microcapsules were premixed with the varnish (for 10 min., at $800 \mathrm{rpm}$ ) using the HS-30D WiseStir mixer (Witeg Labortechnik GmbH, Germany). The application of the varnish with the fragranced microcapsules, onto the printing substrate, was done using an automatic coating technique (K303 Multi Coater, RK PrintCoat Instruments Ltd, UK), with a rod that allows maximum varnish deposition thickness of $12 \mu \mathrm{m}$ (coating speed was $8 \mathrm{~m} / \mathrm{min}$ ). Previously printed samples were coated with the mixture of varnish and four different fragranced microcapsules mass concentrations in the varnish: $0 \%, 1 \%, 7 \%$ and $15 \%$. After coating procedure, all the samples were dried at room temperature $\left(25^{\circ} \mathrm{C}, 55 \%\right.$ relative humidity) for 24 hours.

Selected fragranced microcapsules and the coated samples were prepared and photographed using scanning electron microscopy (SEM; JSM 6060 LV, Jeol, Japan) to obtain microcapsules' and coated samples' morphology. Generated images were also analysed using an image analysis software (ImageJ, USA) (ImageJ, n.d.) in order to determine microcapsules' size/volume distributions. Determination of the fragranced microcapsules diameters was based on the 500 measurements on different SEM images. After SEM analyses, several optical characteristics of the prints were determined in order to investigate the effects of varnish and different microcapsules concetrations application. Following print quality 
parameters were determined: solid-tone print density, tone value increase (TVI) and relative spectral reflectance, using spectrodensitometer SpectroDens (Techkon, Germany).

\section{RESULTS}

\subsection{SEM analysis of the fragranced microcapsules and the coated samples}

Scanning electron microscopy (SEM) and subsequent image analyses of the obtained SEM images were employed in order to investigate the fragranced microcapsules' properties (Figure 1a) in the coated varnish layers, to determine their size/volume distributions (Figure 1b), as well as to investigate the properties of the coated samples' surfaces made by using different fragranced microcapsules mass concentrations in the varnish: 0\% (C_0\% sample), 1\% (C_1\% sample), 7\% (C_7\% sample) and 15\% (C_15\% sample), Figure 2. In the Figure 1 are presented morphology (1a) and size/volume distribution (1b) of the fragranced microcapsules in water suspension, that were used for automatic coating process in combination with the water-based varnish. As it can be observed from the Figure (1a), the fragranced microcapsules have regular, spherical shape, possessing a smooth surface and relatively uniform sizes. Obtained size distribution curve is positively skewed with relatively narrow distribution (blue curve in Figure $1 \mathrm{~b}$ ), where $92.08 \%$ of the sampled fragranced microcapsules had the diameter between $1 \mu \mathrm{m}$ and $3 \mu \mathrm{m}$. The mean diameter of the sampled fragranced microcapsules was $2.08 \mu \mathrm{m}$ (st. dev. 0.63), while the minimum and the maximum recorded diameters were $1.06 \mu \mathrm{m}$ and $4.60 \mu \mathrm{m}$. In contrast to the fragranced microcapsule size distribution, the volume distribution curve (red curve in Figure $1 \mathrm{~b}$ ) is almost symmetrical, showing normal volume distribution, where $17.62 \%$ of all sampled fragranced microcapsules (sizes between $2.5 \mu \mathrm{m}$ and $3 \mu \mathrm{m}$ ) participated with $30.36 \%$ in the total fragranced microcapsules volume amount.

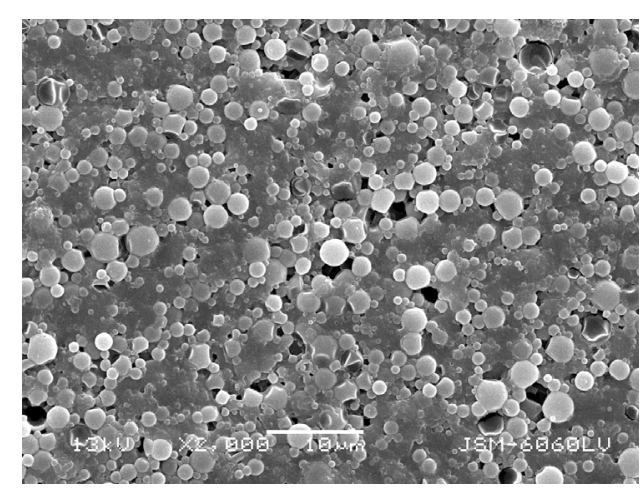

a)

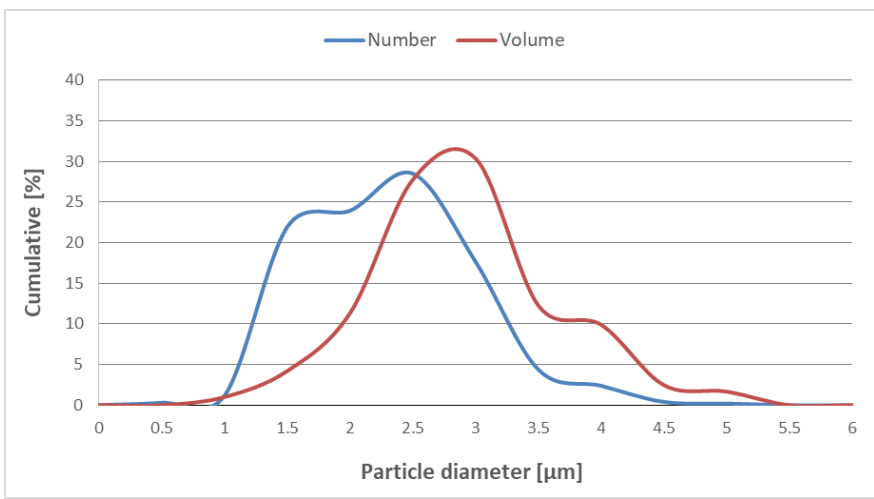

b)

Figure 1: Fragranced microcapsules in water suspension (a) (SEM; 1.000x magnification), with their size and volume distributions (b)

From Figure 2, it can be noticed that used matte coated paper for printing and coating, possesses relatively rough surface structure (Figure 2a), which is also observed in the case of printed sample (Figure 2b) where due to paper's uneven surface structure nonuniform ink deposition of the solid tone patch was obtained (darker, left half of the SEM image). The prints made by solely varnish (Figure 2c), sample C_0\%, has very smooth and uniform surface structure, while the sample coated using varnish and microcapsules in the mass concentration of $1 \%$ (C_1\% sample), Figure $2 d$, has slightly rougher surface structure with several fragranced microcapsules on top of it. The prints made with the fragranced microcapsules in the mass concentration of $7 \%$ (C_7\%), Figure 2e, possess even rougher surface structure, while the samples coated with the varnish and microcapsules in the mass concentration of $15 \%$ (C_15\% sample), Figure $2 \mathrm{f}$, possess the roughest and the least uniform surface structure, with visible fragranced microcapsules spread all over the surface of the sample. By increasing the concentration of the fragranced microcapsules in the varnish, the surface of the coated samples became more and more non-uniform and rough. Transferred microcapsules on the coated samples were undamaged, which prove that automatic coating technique is adequate and can be successfully used for coating process of the fragranced microcapsules. 


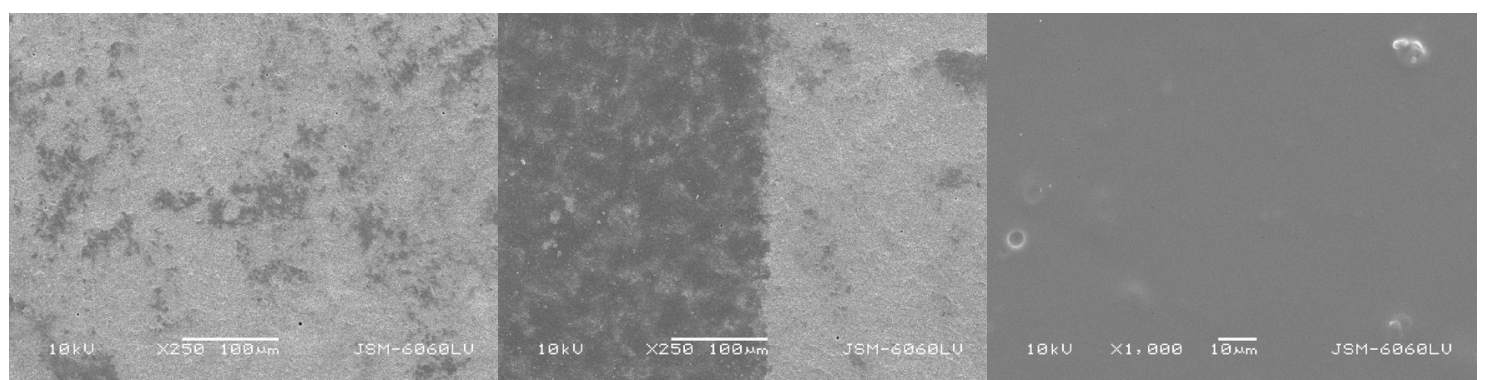

a)

b)

c)

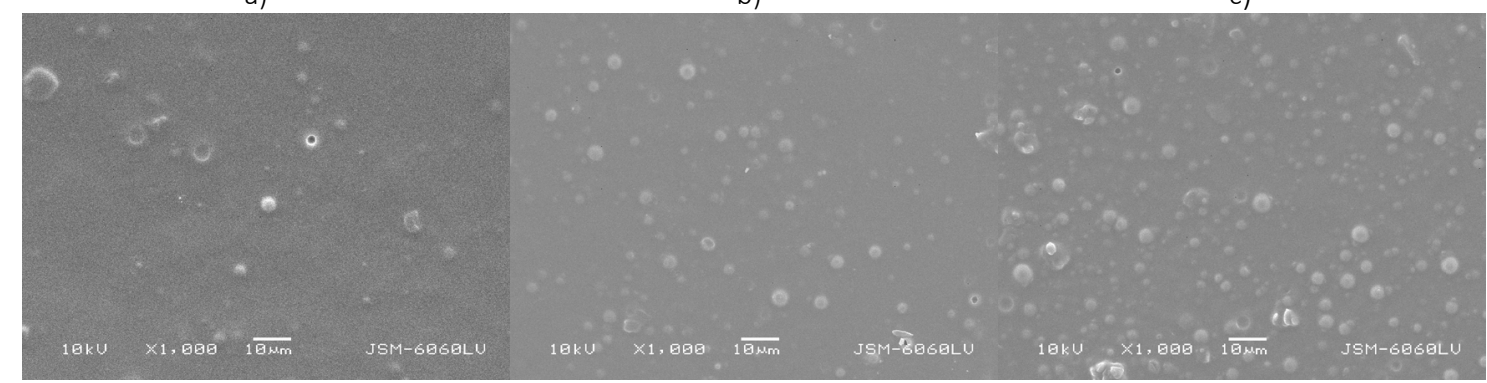

d)

e)

f)

Figure 2: Surfaces of the blank paper (a), printed paper $C(b)$, and printed and coated samples C_0\% (c), C_1\% (d), C_7\% (e), C_15\% (f), (SEM; 250x and 1000x magnifications)

\subsection{Analysis of the print quality parameters}

From the presented solid-tone print density results in Figure 3, it can be observed that all recorded print density values were below reference values (red line) given by ISO standard (ISO 12647-2:2004, 2004). Coating process with the varnish only (without microcapsules) led to solid-tone print density increase (C_0\% sample) which is a result of varnish colour and transparency characteristics. Addition of fragranced microcapsules in the mass concentration of $1 \%$ in the varnish, slightly raised the resulted solid-tone print density value (C_1\% sample), while the coating process with increased microcapsules' concentrations in the varnish (7\% and 15\%) led to gradual print density decline. Varnishing process without fragranced microcapsules produced darker prints compared to uncoated prints, while the higher concentrations of the microcapsules in the varnish (7\% and 15\%) led to gradual print density values drop, which is a result of microcapsules shell material white colour.

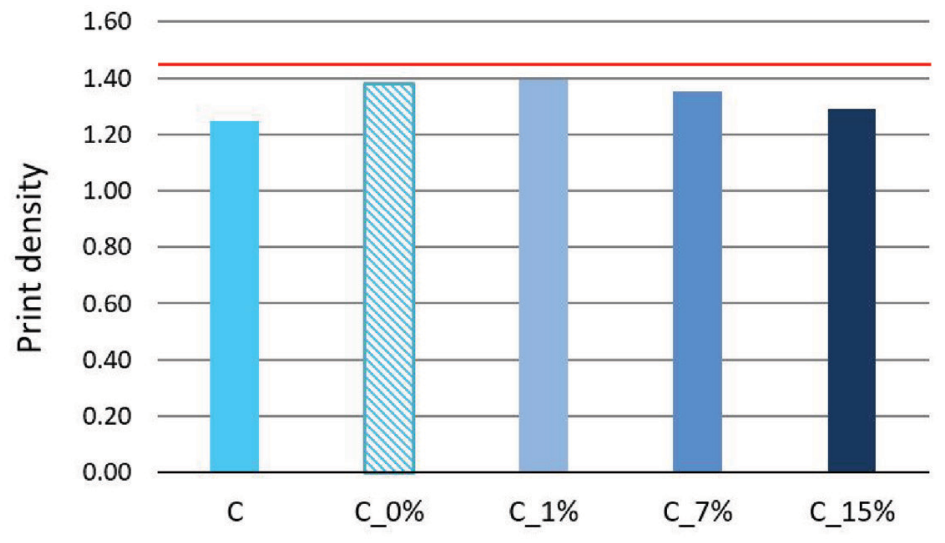

Figure 3: Measured solid-tone print density of printed and coated samples

In Figure 4 are presented obtained TVI values, as well as aimed ISO TVI values (dashed purple line) which correspond to defined printing conditions (printing process, screen ruling, paper and printing plate types) according to ISO standard (ISO 12647-2:2004, 2004). TVI reproduction curve of printed, uncoated sample (C, cyan curve) almost match the reference ISO TVI values (dashed purple line), indicating good print quality, regarding this print quality parameter. Obtained TVI data have a very similar trend as previously 
analysed solid-tone print density data. Namely, coating process using only varnish (C_0\%, dashed cyan curve) produced much higher TVI values over the whole tonal range, comparing to solely printed samples (C sample). The highest TVI values were recorded on the samples coated with varnish and fragranced microcapsules in the mass concentration of $1 \%$ in it (C_1\%, light blue curve). The next increase of the fragranced microcapsules concentration in the varnish (C_7\% sample), led to a decline of TVI values. This trend continued in the case of the samples coated using the highest microcapsules concentration in the varnish as well (C_15\% sample), where the lowest TVI values were obtained, comparing to all coated samples.

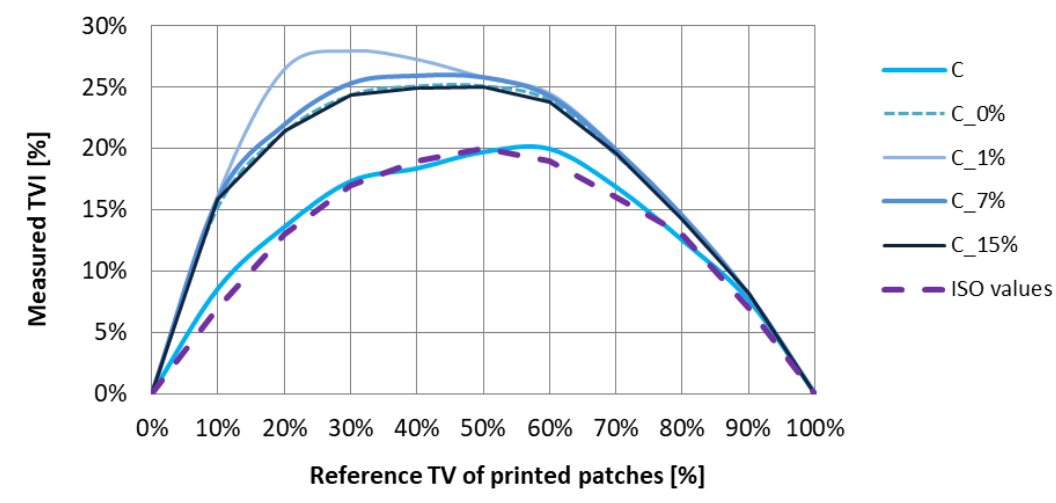

Figure 4: Measured TVI of the samples

In Figure 5 are presented measured relative spectral reflectance values of only printed (C) and printed and coated samples (C_0\%, C_1\%, C_7\% and C_15\%). This parameter was measured on the solid-tone patches printed using an offset printing press and a cyan ink. It can be noticed that all obtained relative spectral reflectance curves have almost identical shape, which describes the measured colour of the printed cyan ink patches (Figure 5).

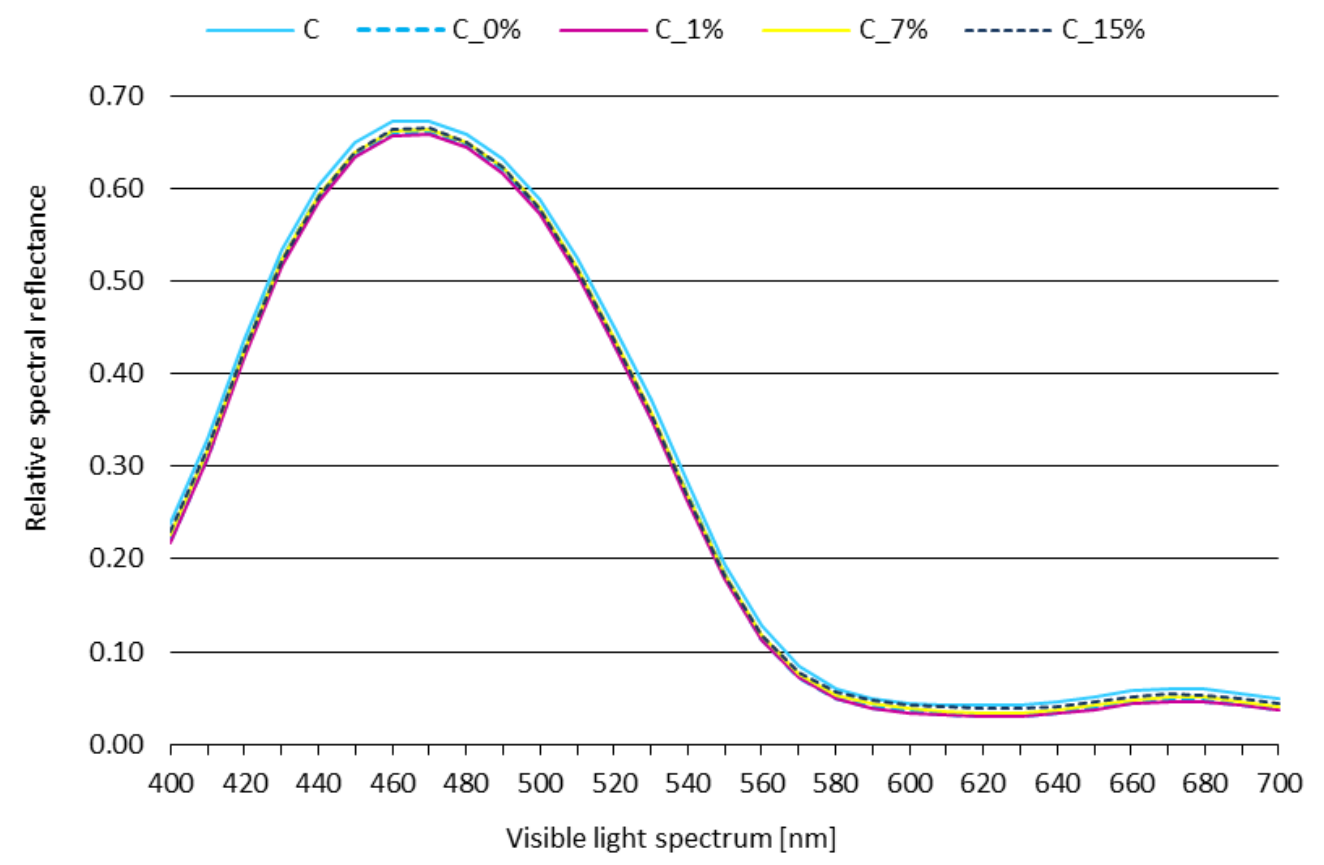

Figure 5: Measured relative spectral reflection of the samples

It can be noticed that on the solely printed sample ( $C$ sample, solid cyan curve) were recorded the highest relative spectral reflectance values, meaning that the colour of this sample was the lightest one. The sample where slightly lower relative spectral reflectance was obtained is the one printed and coated with fragranced microcapsules in the mass concentration of $15 \%$ (C_15\% sample, dashed navy blue curve) 
which is due to high concentration of microcapsules in the varnish that have white coloured shell, so the corresponding intensity of spectral reflectance will be higher compared to the samples coated using varnish with lower microcapsules' quantity. The darkest sample, i.e. the sample where the lowest spectral reflectance values were recorded was the sample printed and coated using fragranced microcapsules in the mass concentration of $1 \%$ (C_1\% sample, solid magenta curve), which almost match the reflectance curve of the slightly lighter sample coated without microcapsules (C_0\% sample, dashed cyan curve).

\section{CONCLUSIONS}

Presented results showed that the automatic coating technique is a nondestructive process for microcapsules transfer and that it can be successfully used for the coating process with varnish and different concentrations of fragranced microcapsules. This was proved by the SEM images where a lot of undamaged microcapsules were transfered on the paper substrate. Used fragranced microcapsules in the water suspension had very regular, spherical shape, smooth surface. Even though a visual inspection of the SEM images showed that microcapsules' sizes are relatively uniform, their size distribution curve is positively skewed with relatively narrow distribution while the volume distribution curve is almost symmetrical (normal volume distribution). The higher the fragranced microcapsules concentration in the coated varnish layer, the higher the surface nonuniformity and roughness of the applied coatings, as well as more microcapsules were observed on the surface of the coated samples.

Coating process with fragranced microcapsules changed to certain extent basic optical characteristics of the printed samples. On the coated samples without fragranced microcapsules were recorded higher solid-tone density values (darker prints) compared to only printed samples, while the higher concentrations of the fragranced microcapsules in the varnish (7\% and 15\%) led to a gradual print density decline, which is a result of white colour of the microcapsules shell material.

Similarly, as in the case of solid-tone print density data, coating process of printed samples led to a dramatic increase of TV, which was even higher after addition of microcapsules in $1 \%$ mass concentration in the varnish. Following two increases of microcapsules' percentage in the varnish (7\% and 15\%), resulted in a slight TVI decrease.

Obtained relative spectral reflectance curves of all samples have almost identical shape, but they have slightly different amplitude. Namely, coating process, without and with small microcapsules concentration of $1 \%$, produces darkest colour samples (the lowest spectral reflectance values), comparing to only printed sample. Higher fragranced microcapsules concentrations in the varnish produced coated samples with a lighter colour (high spectral reflectance values) which is the consequence of the white colour of the microcapsules' shell.

\section{ACKNOWLEDGMENTS}

This research was supported by the Serbian Ministry of Science and Technological Development, Grant No: 35027 "The development of software model for improvement of knowledge and production in the graphic arts industry".

\section{REFERENCES}

[1] Blanco-Pascual, N., Koldeweij, R.B.J., Stevens, R.S.A., Montero, M.P., Gómez-Guillén, M.C., Ten Cate, A.T.: "Peptide Microencapsulation by Core-Shell Printing Technology for Edible Film Application", Food Bioprocess Technology 7(9), 2472-2483, 2014. 10.1007/s11947-014-1256-3.

[2] Boh, B., Šumiga, B.: "Microencapsulation technology and its applications in building construction materials", Materials and Geoenvironment 55(3), 329-344, 2008.

[3] Chovancova, V., Pekarovicova, A., Fleming, I.P.: "Production of 3D Structures in Printing", Proceedings of the 57th TAGA Annual Technical Conference 2005, (Toronto, Ontario, 2008), pages 93-94.

[4] Dubey, R., Shami, T.C., Bhasker Rao, K.U.: "Microencapsulation technology and applications", Defence Science Journal 59(1), 82-95, 2009.

[5] Goetzendorf-Grabowska, B., Krolikowska, H., Gadzinowski, M.: "Polymer Microspheres as Carriers of Antibacterial Properties of Textiles: A preliminary Study", Fibres \& Textiles in Eastern Europe 12(4), 62-64, 2004. 
[6] Goetzendorf-Grabowska, B., Królikowska, H., Bąk P., Gadzinovski, M., Brycki, B., Szwajca, A.: "Triclosan Encapsulated in Poli (L,L-lactide) as a Carrier of Antibacterial Properties of Textiles", Fibres \& Textiles in Eastern Europe 16(3), 102-107, 2008.

[7] Gosh., K.: "Functional coatings by Polymer Microencapsulation", (Wiley-VCH, Weinheim, Germany, 2006.), pages 3; 153; 177; 235.

[8] ImageJ: "Download", URL https://imagej.nih.gov/ij/download.html (last request 2016-06-26).

[9] International Organization for Standardization: ISO 12647-2. "Graphic technology - Process control for the production of half-tone colour separations, proof and production prints - Part 2: Offset lithographic processes", International Organization for Standardization, 2004.

[10] Kipphan, H.: "Handbook of Print Media", (Springer-Verlag Berlin Heidelberg, Germany, 2001.), page 142.

[11] Karlović, I.: "Karakterizacija kolorimetrijskih i geometrijskih osobina oplemenjenih površina u štampi", PhD thesis, Department of Graphic Engineering and Design, University of Novi Sad, Novi Sad, Serbia, 2010.

[12] Karlović, I., Novaković, D.: "Effect of Different Coating Amounts on the Surface Roughness and Print Gloss of Screen Coated Offset Prints", Journal of Imaging Science and Technology 55(2), 020501-1 - 020501-10, 2011.

[13] Manojlović, S.: "Bonding Microcapsules to Different Types of Substrates", BSc Thesis, University of Ljubljana, Slovenia, 2013.

[14] Microtek Laboratories Inc.: "Technical overview: Microencapsulation", URL http://www.microteklabs.com/technical-overview.html (last request 2015-09-24).

[15] Milošević, R., Kašiković, N., Pavlović, Ž., Stankovič Elesini, U., Urbas, R.: "The Possibility of Microcapsules Application Using Pad Printing Technology", Proceedings of the 8th GRID Symposium 2016, (Faculty of technical sciences, Novi Sad, Serbia, 2016), pages 47-55.

[16] McShane, M., Ritter, D.: "Microcapsules as optical biosensors", Journal of Materials Chemistry, 20(38), 8189-8193, 2010. 10.1039/COJM01251C.

[17] Nelson, G.: "Microencapsulation in textile finishing", Review of Progress in Coloration and Related Topics, 31, 57-64, 2001. doi.org/10.1111/j.1478-4408.2001.tb00138.x.

[18] Pavić, N.: "Possibility of Microcapsule Application in Screen and Offset Printing Techniques", MSc thesis, University of Novi Sad, Serbia, 2015.

[19] Peña, B., Casals, M., Torras, C., Gumí, T., Garcia-Valls, R.: "Vanillin release from polysulfone macrocapsules", Industrial and Engineering Chemistry Research 48(3), 1562-1565, 2009. 10.1021/ie801133f.

[20] Rodrigues, S.N., Martins, I.M., Fernandes, I.P., Gomes, P.B., Mata, V.G., Barreiro, M.F., Rodrigues, A.E.: "Scentfashion ${ }^{\circledR}:$ Microencapsulated perfumes for textile application", Chemical Engineering Journal 149(1-3), 463-472, 2009. doi.org/10.1016/j.cej.2009.02.021.

[21] Rose, H.: "Scent Encapsulated in Printed Products", URL https://projekt.beuthhochschule.de/fileadmin/projekt/sprachen/sprachenpreis/erfolgreiche_beitraege_2007/1._Preis_07 _-_Scent_Encapsulated_in_Printed_Products_-_Heike_Rose.pdf, (last request: 2017-04-03).

[22] Satas, D., Tracton, A.A.: "Coatings Technology Handbook", (Boca Raton, FL, USA, 2000.), page 187.

[23] Sensor Products Inc.: "Tactile Pressure Indicating Sensor Film", URL https://www.sensorprod.com/prescale/product-pages/prescale/prescale.pdf (last request 2017-04-04).

[24] Starešinič, M., Šumiga, B., Boh, B.: "Microencapsulation for Textile Applications and Use of SEM Image Analysis for Visualisation of Microcapsules", Tekstilec 54(4-5), 80-103, 2011.

[25] Šumiga, B.: "Informational approaches in the design of chemical microencapsulation processes", PhD thesis, University of Ljubljana, Slovenia, 2013.

[26] Tarnopol, P.B.: "Scenting process", URL http://www.google.com.gt/patents/WO2011002997A1?cl=en (last request 2018-06-10).

[27] Urbas, R., Milošević, R., Kašiković, N., Pavlović, Ž., Stankovič Elesini, U.: “Microcapsules application in graphic arts industry: a review on the state-of-the-art", Iranian Polymer Journal 26 (7), 541-561, 2017. 10.1007/s13726-017-0541-1.

[28] Urbas, R, Stankovič Elesini, U.: "Color differences and perceptive properties of prints made with microcapsules", Journal of Graphic Engineering and Design 6 (1), 15-21, 2015. 


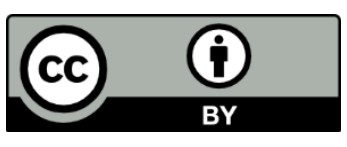

(C) 2018 Authors. Published by the University of Novi Sad, Faculty of Technical Sciences, Department of Graphic Engineering and Design. This article is an open access article distributed under the terms and conditions of the Creative Commons Attribution license 3.0 Serbia

(http://creativecommons.org/licenses/by/3.0/rs/). 